\title{
BLOOD VOLUME AND PLASMA ELECTROLYTE CHANGES IN THE DEHYDRATION OF INFANTS
}

\author{
By RUSTIN MCINTOSH, LASLO KAJDI, AND DOROTHY MEEKER
}

(From the Harriet Lane Home of the Johns Hopkins Hospital and the Department of Pediatrics of the Johns Hopkins University Medical School, Baltimore)

(Received for publication March 20, 1930)

In a general review of the subject of anhydremia published in 1923, Marriott (1) brought out several of the phenomena which had been shown to accompany severe clinical dehydration: an increase in the proportion of the total solids and in the dried weight of a unit volume of blood, an increase in its specific gravity, in red cell count and hemoglobin, and in the concentration of the serum proteins. He showed also, however, that when deprivation of fluid, either from lack of intake, from vomiting, or from diarrhea, persisted over a long period of time, a lowering of total solids, red count, and hemoglobin ensued, which was attributed to breakdown of body protein with the liberation of bound water. All of these phenomena might occur at a time when the plasma volume was subnormal, and consequently an investigation of the concentration of these substances in a unit volume of blood was shown to be of limited value in the study of the water economy as a whole in dehydration. Although these considerations emphasized the fatuity of placing reliance on the indirect evidence afforded by changes in the concentration of blood constituents and the necessity for direct investigation of blood and plasma volume changes in dehydration, such direct determinations have been singularly infrequent. Marriott mentioned some in a general way, but did not fully report his data.

A number of studies made since 1923-for example, those of Hartmann (2) and of Hamilton, Kajdi and Meeker (3)- on the serum or plasma concentration of electrolytes in dehydration accompanying the infections and digestive disorders of infants have shown that a lowering of the total electrolyte concentration is, in fact, rather more com- 
mon than an increase; and even when dehydration was brought about experimentally by reduction of the water intake, Schiff, Bayer, and Fukuyama (4) were unable to change the concentration of serum total fixed base beyond the limit of error of the method used. If, then, a lowering of serum electrolyte concentration of this kind, or even if no change in concentration occurs, one must abandon the concept that loss of water alone from the blood is the primary event in the development of dehydration, since this would only act to bring about a higher concentration of electrolytes. This actual lowering of serum electrolyte concentration in dehydration appeared to Hartmann (2) of sufficient importance to cause him to postulate that loss of electrolyte from the circulation might occur to an extent that required the body to retain nonprotein nitrogen constituents for their osmotic action so that the normal osmotic pressure of the plasma might be maintained. If water alone had been lost to excess, no such difficulty would have existed, for the osmotic pressure of the plasma would by that measure be increased. The lowering of serum electrolyte concentration could theoretically be brought about by dilution of the blood, though in view of the loss of body weight and the obvious loss of water from the body as a whole, this would seem unlikely; or it could result from loss of electrolyte from the circulation. The latter naturally appeared to be the more plausible explanation; but the true answer to the question is not to be obtained by determinations of concentration alone.

Darrow and Buckman (5) attacked this problem by making blood and plasma volume determinations, together with measurements of serum chloride, bicarbonate, protein, conductivity, and freezing point, in patients with dehydration. Their most valuable data were obtained in a small number of patients who, after the initial determination during severe clinical dehydration, responded well to therapy and were subjected to a second analysis from four days to about five weeks later. These patients all showed during the period of dehydration, as compared with values obtained after recovery, a diminution of whole blood, plasma and cell volumes, and a diminution in total circulating serum chloride and protein; while from the point of view of concentration of dissolved substances in the serum during dehydration there was no constant change in chloride, an increase in bicarbonate, and a somewhat less marked increase in protein, with no essential 
change in serum conductivity or freezing point. In the process of recovery they showed that an increase in the total plasma volume was accompanied by; and presumably brought about by, an increase in total plasma water, chloride, and protein in the proportions in which these substances are present in normal plasma. They therefore suggested that the expression "oligemia" more accurately depicts the blood changes accompanying the clinical picture of dehydration. As an explanation of the mechanism of the blood volume and electrolyte changes accompanying the dehydration associated with diarrhea in infants, however, their material as just quoted must be interpreted with some reserve, since two of their patients were older children with encephalitis, one an infant of 16 months with celiac disease, and only one belonged strictly to the clinical class of infantile diarrhea.

We have been able to add to the information pertinent to this subject by further studies of blood and plasma volume, with simultaneous determinations of serum electrolyte concentration, during clinical dehydration in infants with diarrhea and after recovery.

\section{METHODS}

Infants with dehydration, manifested by loss of skin turgor, dryness of mucous membranes, depression of the fontanel, and recession of the eyeballs, were subjected immediately on admission, and before any parenteral fluid had been given, to the withdrawal of about $10 \mathrm{cc}$. of blood for estimation of serum electrolyte concentration, and to determination of the blood volume by the carbon monoxide method (6). Hematocrit determinations, on which the calculation of plasma volume was based, were made in a few instances by the Van Allen method (7) but in the majority of cases by the heparin method of Went and Drinker (8). Serum total base concentration was determined by Fiske's method (9), chloride by the method of Fiske and Sokhey (10), bicarbonate in $0.2 \mathrm{cc}$. samples by Van Slyke and Neill's method (11), and protein by the method of Greenberg (12). These data permitted the calculation of plasma and cell volumes, and of the total amount of circulating fixed base, chloride, bicarbonate, protein anions, and by difference the undetermined acid fraction, comprising mainly the organic acids, phosphates, and sulphates. In the calculation of bicarbonate, it was assumed that all of the carbon dioxide 
liberated in the customary determination of the carbon dioxide combining power was present as bicarbonate ions, regardleśs of serum $\mathrm{pH}$; the inaccuracy so introduced involves no significant error in the final calculations. For the calculation of the proportion of the total protein present as anions, the formula of Van Slyke, Hastings, Hiller, and Sendroy (13) was used, assuming an albumin globulin ratio of 1.6 and a $\mathrm{pH}$ of 7.34 ; here again, no significant error is introduced by basing our calculations on these assumptions. It was further assumed that determinations of serum electrolyte concentration could be applied to calculations of plasma electrolyte content without altering their significance. Following these determinations, the patients were treated symptomatically for the relief of dehydration through attention to the underlying infection and by the parenteral administration of normal salt solution, occasionally also with the use of glucose solutions or blood transfusions. At the end of a week or more, when clinical signs of dehydration had completely disappeared, the analytical procedures were repeated in order to obtain figures that might be regarded as normal standards for these individuals. The diet during the period of treatment was not uniform, but in the great majority of cases consisted of a mixture of whole milk with 8.5 per cent of cane sugar added, given first, after a preliminary starvation period of approximately 24 hours, in amounts yielding 20 calories per kilogram per day and increased by daily steps of 10 to 20 calories per kilogram per day up to full caloric requirements. All patients were given as much water by mouth as they could be induced to take; occasionally normal salt solution or 3 per cent glucose solution was substituted for tap water.

The error of the carbon monoxide method of blood volume determination cannot be checked in any entirely satisfactory way, but from theoretical considerations it is estimated to be less than 8 per cent, and the same figure probably applies also to plasma volumes determined by this method. The chief source of inaccuracy is undoubtedly the fitting of the breathing mask to the patient's face and the problem of keeping it adjusted. This being so, we have been satisfied to forego attempts to increase the accuracy of other phases of the determination at the expense of the removal of larger amounts of the patient's blood. On these grounds we have assumed an average value, based 
on 54 determinations in normal individuals, for the $\mathrm{CO}$ content of the infant's blood prior to the administration of $\mathrm{CO}$ in the course of the test, and we have only single determinations of the blood $\mathrm{CO}$ concentration at the end of the test. The effect of the chief errors of the procedure is to give false high blood volume figures, and we must admit the possibility that some of our results err in this direction; on the other hand, a false low result is most unlikely.

\section{CLINICAL PROTOCOLS}

There were 11 patients in the series, ranging in age from 2 to 14 months at the time of admission. ${ }^{1}$ All of them had diarrhea, most of them showed some form of parenteral infection, while a few had bacillary dysentery. Most of them showed some degree of vomiting. The severity of dehydration was graded from 1 to 4 , corresponding roughly to a scale of "slight," "mild," "moderate," and "severe." A few of the patients gave perhaps mild but typical pictures of "acute intestinal intoxication;" this applies to cases 1, 2, 4, 5, 9 and 11. The order of arrangement of cases in the following series is based on the change found in plasma volume during dehydration.

Case 1. L. G., girl, age 8 months, had had diarrhea with vomiting for a month. She had been nursed for 2 months, then put on a feeding of milk, water, and cane sugar. Admission temperature $38.6^{\circ} \mathrm{C}$.; dehydration grade 4; very toxic, almost moribund. It is likely that pneumonia, the signs of which became definite a day or two later, was present at this time. After the first blood analyses, the patient was vigorously treated with fluids by intravenous and intraperitoneal injections of salt solution and by transfusion of $150 \mathrm{cc}$. of citrated blood. During the course of her illness she developed bilateral otitis media and an acute stomatitis. Parenteral fluids were no longer required after the first week. The second set of blood determinations was made 11 days after admission. (Fig. 1.)

Case 2. J. K., boy, age $2 \frac{1}{2}$ months, had had vomiting and diarrhea for a little over 24 hours, with convulsions occurring shortly before admission. He had been fed since birth on a weak dilution of condensed milk, lately one teaspoon in four ounces of water, and had been offered the breast once a day. Admission temperature $39.5^{\circ} \mathrm{C}$; dehydration grade 4 ; toxic behavior; no demonstrable infection. After determination of blood volume and serum electrolyte concentration, he was given normal salt solution intraperitoneally and intravenously, and from time to time during the first eight days intraperitoneal and subcutaneous injections were

${ }^{1}$ We have omitted from this report the records of three patients whose cell volume figures were so high as to justify the suspicion of gross leakage of gas in the measurement of blood volume. 
repeated. The second set of determinations was made 13 days after the first. (Fig. 2.)

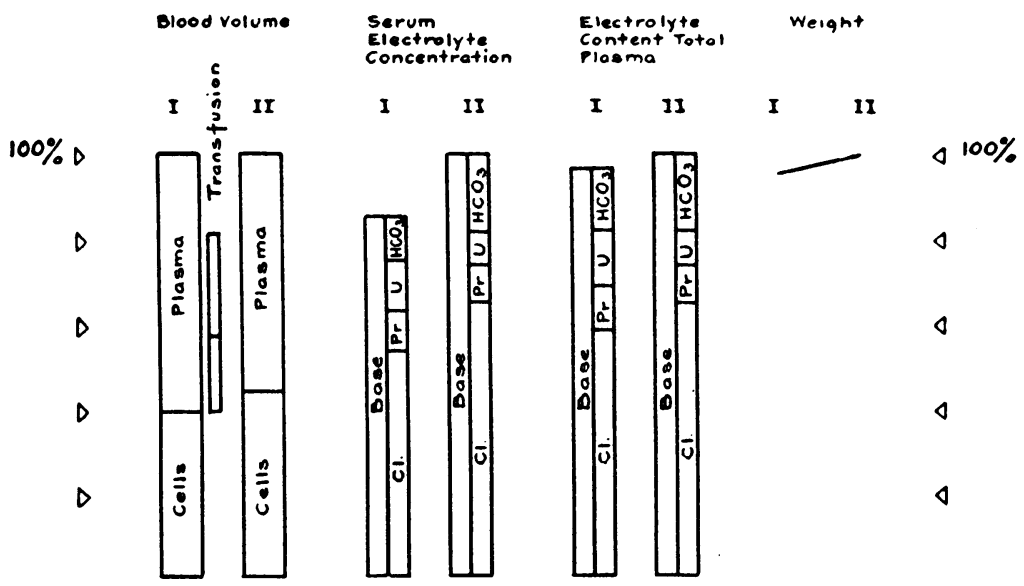

Fig. 1. L. G. Age, 8 Months. Dehydration, Grade 4. Interval Between I and II, 11 Days. Transfusion Immediately After I.

Salt Solution Parenterally

In all the figures the determinations are represented in an identical way. The first pair of columns depicts total blood volume, separated into cell and plasma volumes. The second pair shows the serum concentration of electrolytes, the height of the columns or subdivisions expressing molar equivalents as cubic centimeters of $\mathrm{N} / 10$ solution. $\mathrm{Pr}=$ base bound by protein; $\mathrm{U}=$ residual anion. The third pair represents the total plasma content of electrolytes in circulation at the time of the test, and is obtained by multiplying the plasma volume by the serum electrolyte concentration. In each of the three pairs of columns, the one on the right, representing determination number II made after recovery, is plotted on a scale chosen to show a 100 per cent value for total blood volume, fixed base concentration in the serum, and total plasma content of fixed base. The results of determination number I, representing the conditions during dehydration, are then plotted to the same scale so that the eye can readily measure the approximate percentage deviation from the recovery value. The curve of weight change is similarly treated, the recovery figure being given the 100 per cent value. Where transfusions have been given between the two determinations, they are plotted in to scale between the blood volume columns. The exact figures for the calculated percentage deviations are reported in tables 1 and 2.

Case 3. M. A., girl, age 5 months, had had diarrhea for 9 days. She had been nursed only four days, and had then been put on whole cow's milk with added 
sugar. Admission temperature $36.6^{\circ} \mathrm{C}$; dehydration grade 3 ; slightly toxic; no demonstrable infection. After the first blood determinations, she was given an

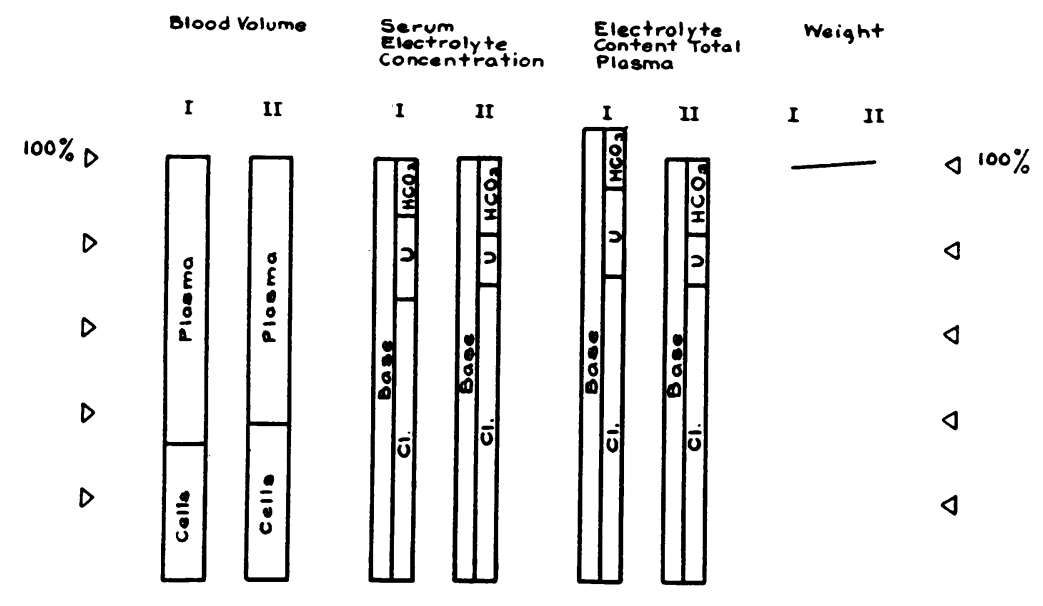

Fig. 2. J. K. Age, $2 \frac{1}{2}$ Months. Dehydration, Grade 4. Interval Between I and II, 13 Days. Salt Solution Parenterally. TeMPerature $39.5^{\circ}$ To $36.8^{\circ} \mathrm{C}$.

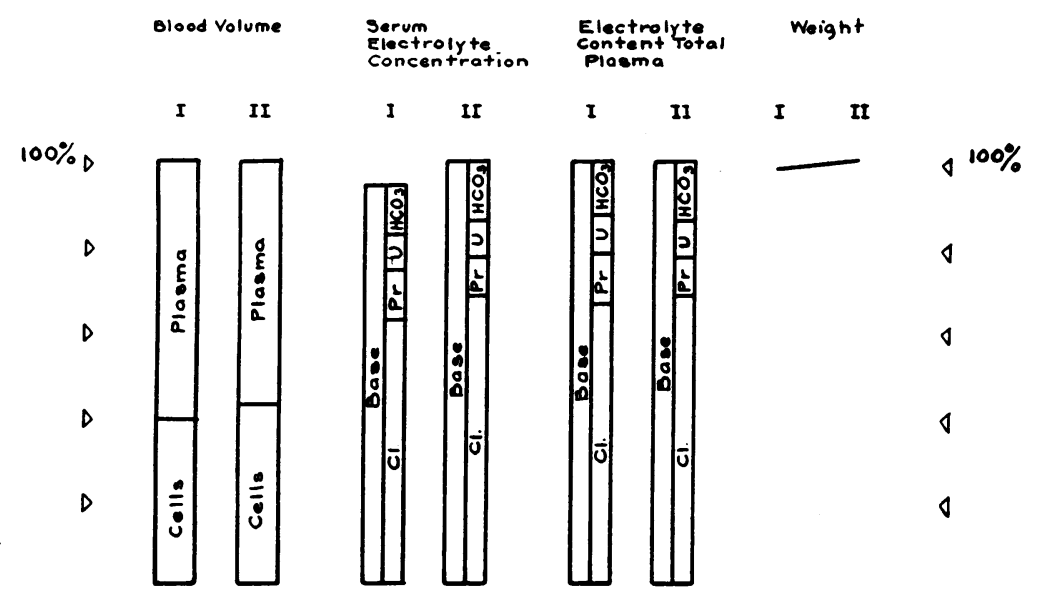

Fig. 3. M. A. Age, 5 Months. Dehydration, Grade 3. Interval Between I and II, 10 Days. Salt Solution Parenterally

intraperitoneal injection of salt solution, which was repeated three days later. The second set of determinations was made 10 days after admission. (Fig. 3.) 
Case 4. J. R., boy, age 3 months, had been having diarrhea for three weeks before admission. He had been nursed up to a week before admission, but the breast milk supply was suspected of being inadequate. When symptoms commenced, he was at first given supplemental feedings of protein milk; in the week preceding admission, he had been weaned to bottle feedings of protein milk, buttermilk, and finally barley water alone, without relief of symptoms. Admission temperature $37.0^{\circ} \mathrm{C}$; dehydration grade 4 ; toxic behavior; congestion of pharynx; thrush; weight 2800 grams, showing that this was an acute illness grafted on a severe chronic nutritional disturbance. After the first set of blood determinations he was given $250 \mathrm{cc}$. of normal salt solution intraperitoneally and a transfusion of $50 \mathrm{cc}$. of citrated blood. Parenteral fluid injections were repeated from

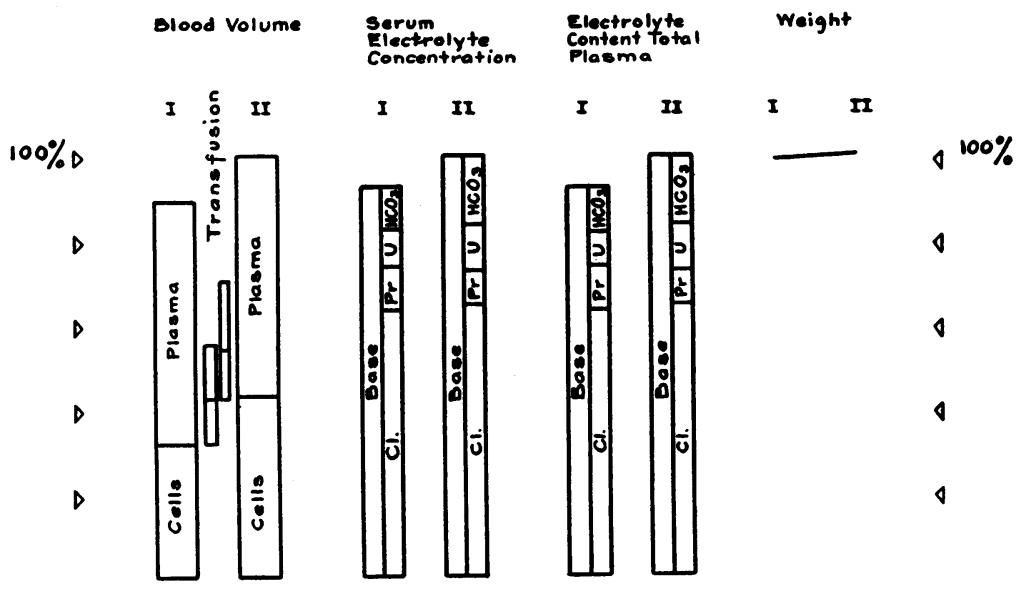

Fig. 4. J. R. Age, 3 Months. Dehydration, Grade 4. Interval Between I aNd II, 10 Days. Transfusion, 18 cc./Kgm. Salt Solution Parenteraliy

time to time during the first four days, and a second transfusion of $60 \mathrm{cc}$. was given three days after admission. The second determinations were made after an interval of 10 days. (Fig. 4.)

Case 5. C. F., girl, age $13 \frac{1}{2}$ months, had been having diarrhea for 5 days, with fever up to $39.7^{\circ} \mathrm{C}$. She had been nursed ever since birth, and had also had a variety of table food since the age of 9 months. Admission temperature $39.2^{\circ} \mathrm{C}$.; dehydration grade 2 ; markedly toxic behavior; bronchopneumonia; B. dysenteriae, Flexner type, isolated from stools. After the first blood analyses, she was given an intravenous injection of $\mathbf{5}$ per cent glucose solution and a subcutaneous one of normal salt solution. The latter was repeated five times in the next ten days. At the end of two weeks the frequency of the movements had greatly diminished, 
all clinical signs of dehydration had disappeared and she appeared to be thriving, although she was still passing mucus and occasionally blood. The second set

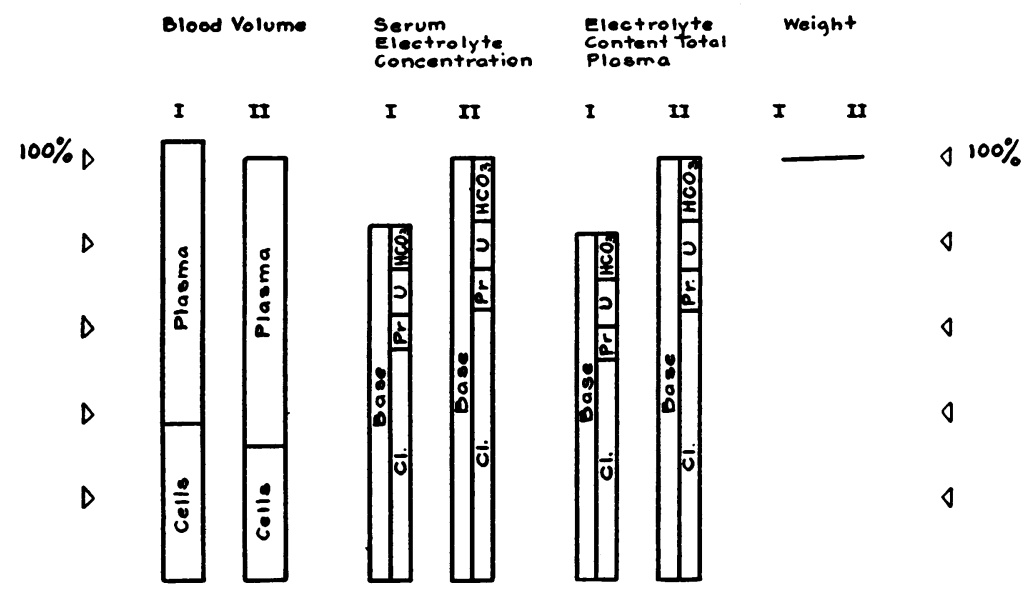

Fig. 5. C. F. Age $13 \frac{1}{2}$ Months. Dehydration, Grade 2. Interval Between I and II, 15 Days. Glucose and Salt Solution Parenterally

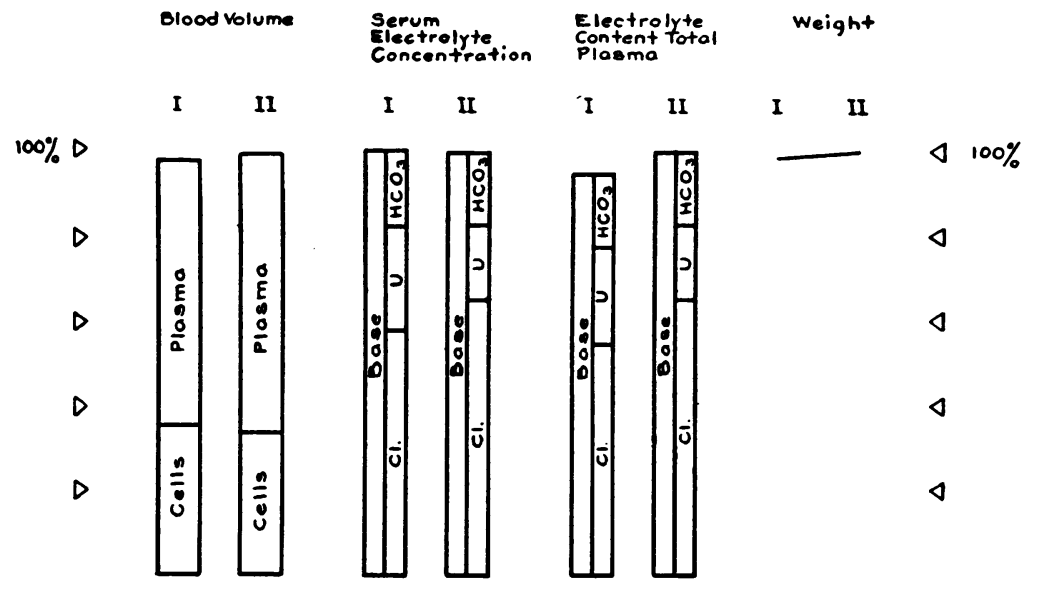

Fig. 6. R. M. Age, 4 Months. Dehydration, Grade 4. Interval Between I AND II, 9 Days. Salt Solution Parenterally

of determinations of blood volume and electrolyte concentration was made 15 days after admission. (Fig. 5.) 
Case 6. R. M., boy, age 4 months, had had diarrhea for 8 days and vomiting for 3 days before admission. He had been nursed for 6 weeks, then fed on condensed milk mixtures. Admission temperature $39.5^{\circ} \mathrm{C}$.; dehydration grade 4: moderately toxic behavior; slight degree of congestion of pharyngeal mucous membrane; B. dysenteriae, Y type, isolated from stools. After the first blood determinations he was given an intraperitoneal injection of normal salt solution. Parenteral administration of salt solution was repeated three times in the first five days. By the ninth day, when the blood analyses were repeated, the signs of dehydration had disappeared and the diarrhea had greatly diminished in severity. (Fig. 6.)

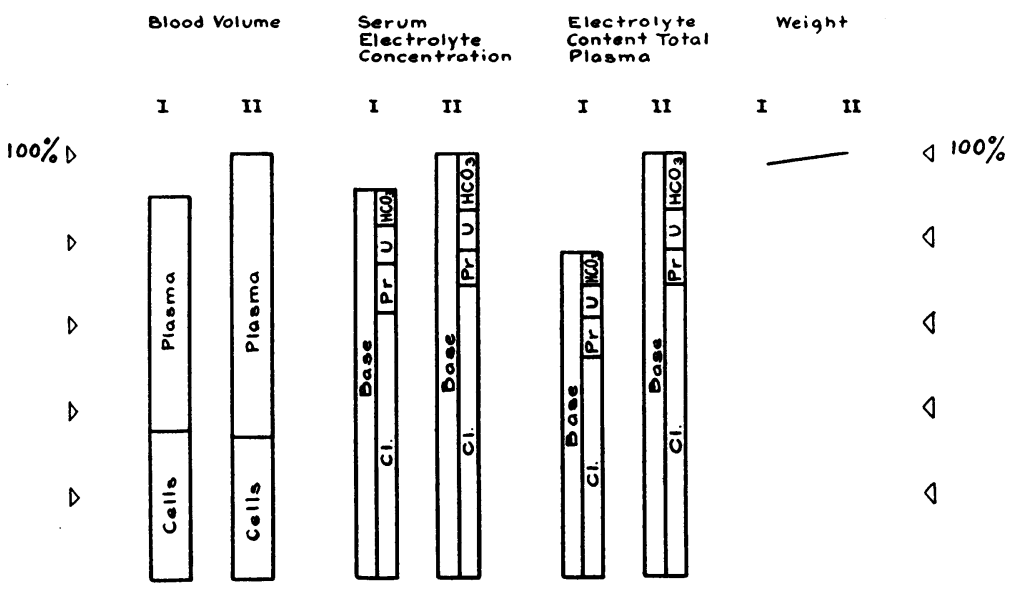

Fig. 7. F. B. Age, 2 Months. Dehydration, Grade 3. Interval Between I and II, 9 days. Salt Solution Parenterally

Case 7. F. B., girl, age 2 months, had been having diarrhea for two weeks, vomiting for one week. She had been nursed 4 weeks, then put on a milk-watercane sugar mixture. Admission temperature $37.2^{\circ} \mathrm{C}$.; dehydration grade 3; no toxic signs; the appearance of the stools, and the absence of evidence of infection elsewhere, led to a clinical diagnosis of bacillary dysentery which, however, was never substantiated bacteriologically. After the first blood determinations she was given an intraperitoneal injection of normal salt solution, with sufficiently satisfactory effect that it did not require repetition. The second blood determinations were made 9 days after the first. (Fig. 7.)

Case 8. B. J., girl, age 2 months, had had diarrhea for 6 days, vomiting and fever for 4 days. She had been nursed for one month, then put on a mixture of milk, water and cane sugar; she had also been getting orange juice, prune juice, 
and a preparation of irradiated ergosterol daily for one month. Admission temperature $38.0^{\circ} \mathrm{C}$; dehydration grade 2 ; not particularly toxic; respirations slightly increased in depth; no parenteral infection found. After determination of blood volume and serum electrolyte concentration, she was given an intraperitoneal injection of normal salt solution with temporary relief of dehydration. Parenteral administration of salt solution was resorted to five times in the first seven days. No other type of fluid was used, nor was alkali given by mouth. The second set of blood determinations was made 16 days after the first. (Fig. 8.)

Case 9. W. E., boy, age 7 months, had had fever and diarrhea for four days, vomiting for three days. He had been nursed for two months, then put on a

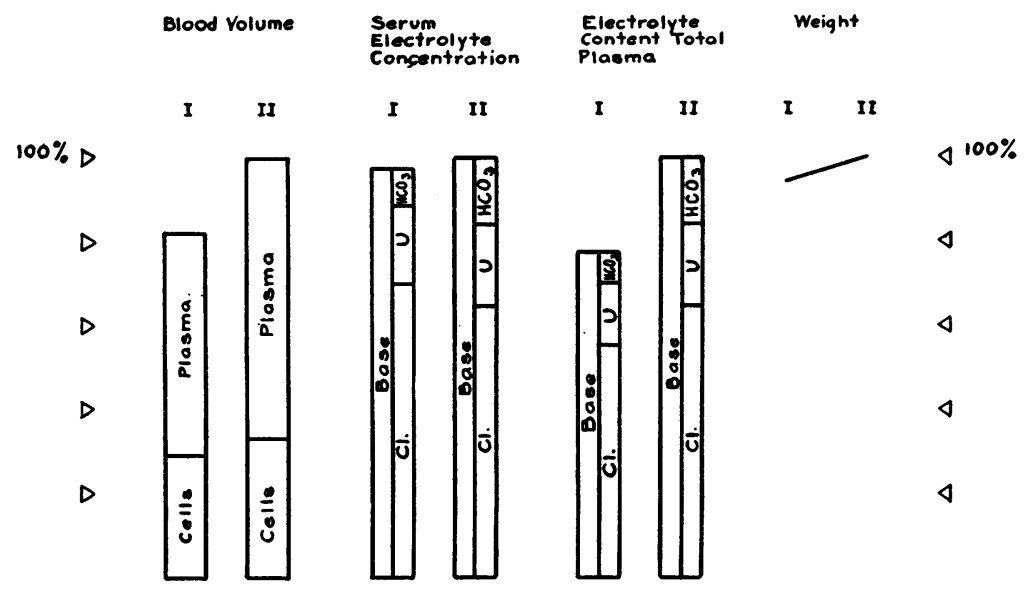

Fig. 8. B. J. Age, 2 Months. Dehydration, Grade 2. Interval Between I AND II, 16 Days. Salt Solution Parenterally

mixture of milk, water, and dextrimaltose; recently he had been getting a little supplemental solid food. Admission temperature $38.0^{\circ} \mathrm{C}$.; dehydration grade 2; markedly toxic behavior; no parenteral infection found. After the initial determination of blood volume and serum electrolyte concentration, he was given 5 per cent glucose solution intravenously and normal salt solution intraperitoneally. The response was unusually well sustained, no further parenteral fluid administration being required. The diarrhea had subsided by the end of four days. The second set of blood analyses was made 8 days after admission. (Fig. 9.)

Case 10. M. K., girl, age $8 \frac{1}{2}$ months, had had diarrhea and marked prostration for three days. She had been nursed for two months; the subsequent feeding history could not be satisfactorily obtained. Admission temperature $37.4^{\circ} \mathrm{C}$.; 
dehydration grade 2; not markedly toxic at first, but both dehydration and prostration increased in the first five days; pyuria was first discovered four days after

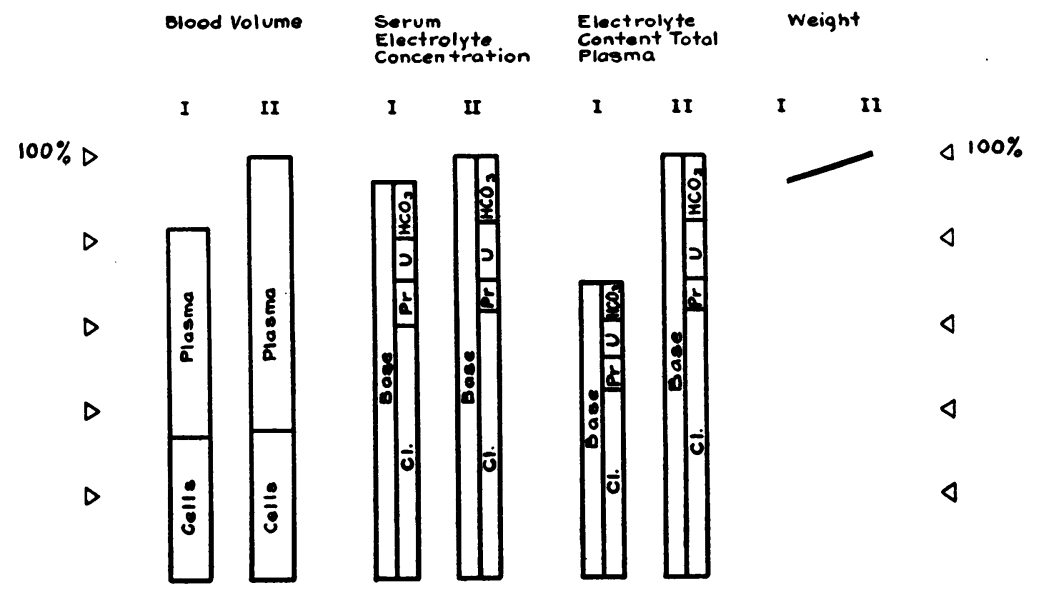

Fig. 9. W. E. Age, 7 Months. Dehydration, Grade 2. Interval Between I and II, 8 Days. Glucose and Salt Solution Parenteraliy

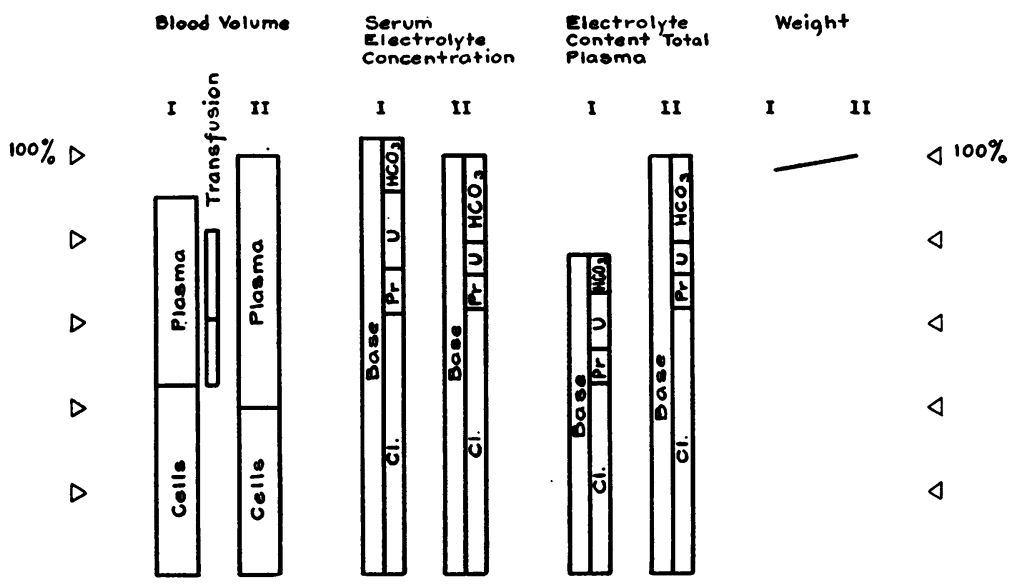

Fig. 10. M. K. Age, $8 \frac{1}{2}$ Months. Dehydration, Grade 2. Interval Between I and II, 17 Days. Transfusion 4 Days After I. Salt Solution Parenterally

admission. After the first set of blood determinations she was given an intravenous injection of normal salt solution. During the first nine days in the hos- 
pital she required parenteral administration of fluids eight times, and a transfusion of $200 \mathrm{cc}$. of citrated blood was given on the fourth day after admission. Both the diarrhea and dehydration had cleared up at the end of two weeks, and the second set of blood analyses was made 17 days after the first. (Fig. 10.)

The subsequent course of this patient has established the basic diagnosis as pyelonephritis secondary to ureteral stricture. None of the subsequent febrile attacks, of which there have been several, has been associated with dehydration of any severe degree.

Case 11. G. V., boy, age 14 months, had had diarrhea for 5 days and vomiting for one day. He had been nursed since birth and had had indefinite amounts of

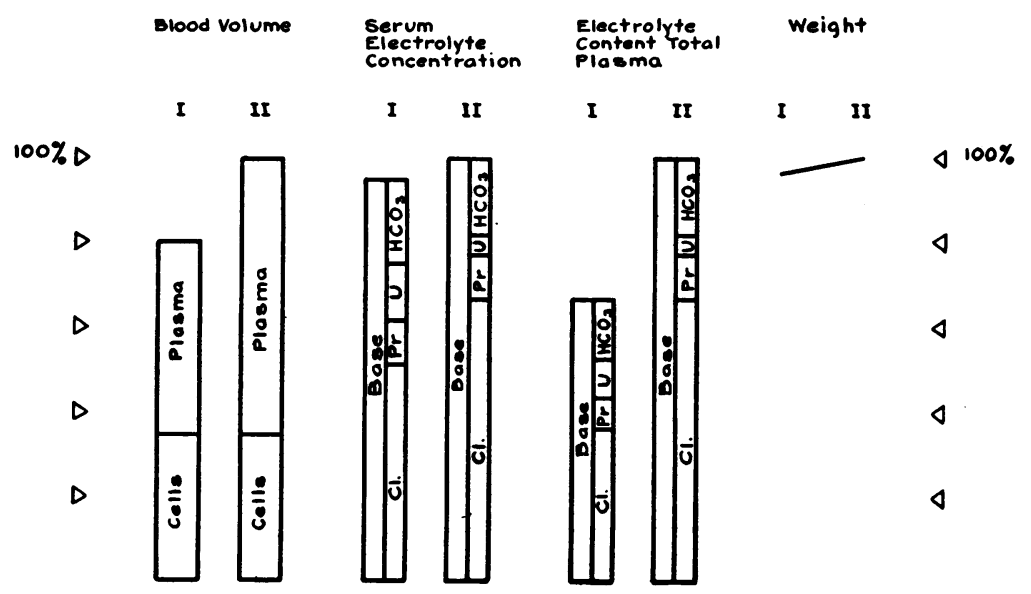

Fig. 11. G. Age, 14 Months. Dehydration, Grade 1. Interval Between I aNd II, 23 Days. Glucose and Salt Solution Parenterally

table food in addition. Admission temperature $38.2^{\circ} \mathrm{C}$.; dehydration grade 1; in contrast, the toxic behavior was marked; B. dysenteriae, $\mathrm{Y}$ type, isolated from the stools. After the first blood analyses, he was given 5 per cent glucose solution intravenously and normal salt solution intraperitoneally. Although the toxic symptoms cleared up quickly, diarrhea and dehydration persisted for several days. A week after admission the skin and subcutaneous tissues showed a more marked degree of dehydration than on admission; yet the patient spent a good part of the day standing up in his crib. Parenteral administration of salt solution was repeated on the ninth day. The second set of blood analyses was made 23 days after the first. (Fig. 11.) 


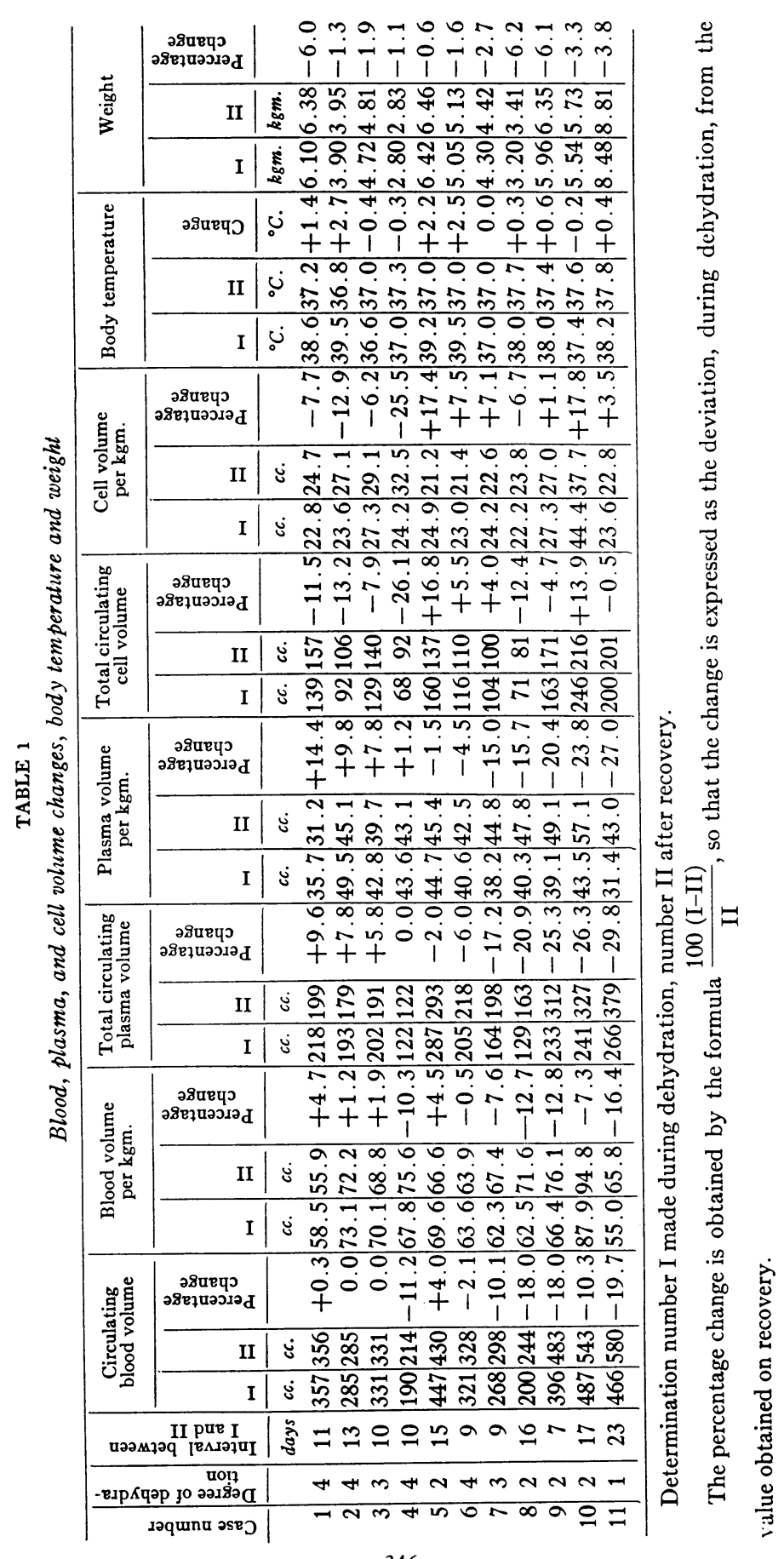




\section{ANALYSIS OF RESULTS}

Blood volume. In table 1 are given the figures for absolute blood volume and blood volume per kilogram of body weight. It will be seen that there is not a constant direction of deviation, during dehydration, from the recovery value; some patients showed no significant alteration, others a marked decrease in the total amount of blood in circulation. The average change proves to be a decrease of about 8 per cent below the value after recovery, but this figure has little significance as an average in view of the dispersion of the results between the extremes of +4 and -20 per cent. No correlation was found between the amount of reduction in circulating blood volume and the severity of dehydration as judged by the usual clinical standards. It is evident from these data that the volume of circulating blood need not necessarily show a diminution even when the subcutaneous tissues are markedly dehydrated (cases 1,2,6). For further analysis of the changes in the total volume of circulating fluid, the plasma and cellular components are considered separately.

Plasma volume. Two of the patients showed an apparently significant increase in plasma volume during dehydration (table 1), four of them no significant change, and five a distinct diminution. The work of previous investigators on the dehydration of infants and children (5) and on that of adults in diabetic coma (14) had led us to anticipate a reduction of plasma volume wherever, as in our series, signs of dehydration of the subcutaneous tissues were present. In the light of our own studies, however, we believe that this view must be modified. On comparison of the plasma volume changes with changes in cell volume (table 1), it will be seen that of the first three patients, two of whom showed a significant increase and one a questionable increase in plasma volume during dehydration, all showed a diminution of cell volume. If our results had been the outcome of experimental error in the determination of the blood volume, both plasma and cell volume changes would have been in the same direction, and their divergence is to this extent a confirmation of their validity. It is likely that in patients with dehydration as it is encountered in clinical studies of disease there are in simultaneous operation, in addition to the forces tending to lower the plasma volume on account of the demand for 
fluid in other parts of the body, other influences acting in the direction of plasma volume increase. We have shown in experimental animals (15), as Soule, Buckman and Darrow (16) and as Eppinger and Schürmeyer (17) have shown in man, that in the presence of fever the plasma volume tends to be augmented. Many of our patients, as will be seen from Table 1, did have fever at the time the first blood volume

$\mathrm{T}$

Changes in serum electrolyte concentrati

\begin{tabular}{|c|c|c|c|c|c|c|c|c|c|c|c|c|c|c|c|c|c|c|}
\hline \multirow[b]{2}{*}{ है } & \multicolumn{3}{|c|}{$\begin{array}{l}\text { Total fixed base } \\
\text { serum }\end{array}$} & \multicolumn{3}{|c|}{$\begin{array}{l}\text { Chloride } \\
\text { serum }\end{array}$} & \multicolumn{3}{|c|}{$\begin{array}{l}\text { Bicarbonate } \\
\text { serum }\end{array}$} & \multicolumn{3}{|c|}{$\begin{array}{l}\text { Protein anions } \\
\text { serum }\end{array}$} & \multicolumn{3}{|c|}{$\begin{array}{l}\text { Undetermined acids } \\
\text { serum }\end{array}$} & \multicolumn{3}{|c|}{$\begin{array}{l}\text { Undetermined ac } \\
\text { serum (protein n } \\
\text { determined) }\end{array}$} \\
\hline & I & II & 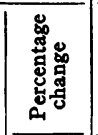 & I & II & 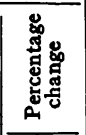 & I & II & 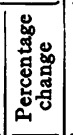 & I & II & 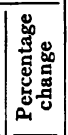 & I & II & 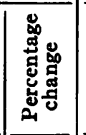 & I & II & \\
\hline & $\left|\begin{array}{c}c c \\
\text { sitio } \\
\text { per } \\
100\end{array}\right|$ & $\begin{array}{c}c c . \\
\text { s/10 } \\
p e r \\
100\end{array}$ & & $\left|\begin{array}{c}c c . \\
x / 10 \\
p e r \\
p e r\end{array}\right|$ & $\begin{array}{c}c c . \\
\text { sitio } \\
\text { per } 100\end{array}$ & & $\begin{array}{c}c c . \\
N / 10 \\
\text { per } 100\end{array}$ & $\begin{array}{c}c c \\
\text { N/10 } \\
\text { per } 100\end{array}$ & & $\begin{array}{c}c c . \\
\text { N/10 } \\
\text { per } 100\end{array}$ & $\begin{array}{c}c c \\
\text { Ne/10 } \\
\text { per } 100\end{array}$ & & $\begin{array}{c}c c \\
N / 10 \\
p e r \\
\text { per } 100\end{array}$ & $\mid \begin{array}{c}c c \\
\text { N/id } \\
\text { per } 100\end{array}$ & & $\mid \begin{array}{c}c c \\
\text { s } \\
\text { per } 100\end{array}$ & $\begin{array}{c}c c \\
\text { Ner } \\
\text { per } 100\end{array}$ & \\
\hline & $c c$. & $c c$. & & & & & & & & & & & & cc. & & & & \\
\hline 1 & 137 & 155 & -11.6 & 83 & 101 & $|-17.8|$ & 21.0 & 28.8 & -27 & $\mid 14.6$ & 13.2 & +11 & \begin{tabular}{|l|}
$\mid 18.4$ \\
\end{tabular} & 12.0 & +53 & & & \\
\hline 2 & $\mid 147$ & 148 & $-0.7 \mid$ & 99 & 104 & -4.8 & \begin{tabular}{|l|}
19.2 \\
\end{tabular} & 26.8 & -28 & & & & & & & $|38.8|$ & 17.4 & - \\
\hline 3 & 147 & 156 & -5.8 & 97 & 106 & -8.5 & $\mid 18.6$ & 22.3 & $\mid-17$ & 18.6 & 14.6 & +27 & 12.8 & 13.1 & -2 & & & \\
\hline 4 & $\mid 145$ & 157 & -7.6 & 99 & 101 & -2.0 & $\mid 16.0$ & 25.7 & $|-38|$ & 16.0 & 12.7 & +26 & $\mid 14.0$ & 17.6 & -20 & & & \\
\hline 5 & $|139|$ & 166 & -16.3 & 89 & 106 & -16.0 & \begin{tabular}{|l|}
18.9 \\
\end{tabular} & 25.2 & -25 & 12.7 & 15.8 & -20 & 18.4 & 19.0 & -3 & & & \\
\hline 6 & $\mid 158$ & 157 & +0.6 & 91 & 102 & -10.8 & 28.4 & 27.0 & +5 & & & & & & & 38.6 & 28.0 & \\
\hline 7 & $\mid 140$ & 152 & -7.9 & 95 & 105 & -9.5 & $\mid 13.6$ & 21.0 & -35 & \begin{tabular}{|l|}
16.9 \\
\end{tabular} & 12.0 & +41 & 14.5 & 14.0 & +4 & & & \\
\hline 8 & $|157|$ & 161 & -2.5 & 112 & 104 & +7.7 & $\mid 14.3$ & 25.8 & -45 & & & & & & & $|30.7|$ & 31.2 & \\
\hline 9 & 155 & 165 & -6.1 & 99 & 105 & -5.7 & 22.4 & 24.1 & $-7 \mid$ & 17.2 & 12.0 & +43 & $|16.4|$ & 23.9 & $\mid-31$ & & & \\
\hline 10 & 162 & 156 & +3.8 & 97 & 99 & -2.0 & $\mid 19.6$ & 32.0 & -39 & 16.9 & 12.9 & +31 & 28.5 & 12.1 & +136 & & & \\
\hline 11 & 147 & 155 & -5.2 & 79 & 103 & -23.3 & 31.1 & 28.7 & +8 & 16.2 & 16.2 & & 20.7 & 7.1 & +192 & & & \\
\hline
\end{tabular}

Determination number I made during dehydration, number II after recovery.

The results of determinations are expressed in cubic centimeters of $\mathrm{N} / 10$ solution.

The percentage change is obtained by the formula $\frac{100 \text { (I-II) }}{\text { II }}$, so that the change is expressed as the devis

determination was made; though it is likewise true that this was not confined to those patients showing an increase of plasma volume during dehydration. The two patients, cases 1 and 2, however, who showed a significant increase, also had fever. The most marked losses of plasma volume were found in patients with temperatures lying between 37.0 and $38.2^{\circ} \mathrm{C}$.

Two general methods of visualizing the mechanism of plasma water 
amounting to 25 or 30 per cent in some instances, will be of more interest when discussed later in conjunction with parallel changes in plasma electrolytes.

Cell volume. Both increases and decreases were found. While the percentage changes between the two sets of determinations were in many cases quite marked, the absolute changes were not large enough to alter materially our interpretation of parallel plasma volume behavior, even supposing that a replacement of plasma by cells were shown to be a normal physiological exchange. It is not likely that in our patients rapid changes of cell volume were taking place, except in those mentioned as having been transfused. The interval between determinations was long enough, however, to explain changes dependent on more slowly-acting forces, either in the direction of cell volume increase from growth of the blood as a tissue or in the direction of diminution from blood destruction as it occurs in infections.

Electrolyte concentration. The changes in the serum concentration of total fixed base, chloride, bicarbonate, protein anions, and undetermined acid fraction (table 2) are similar to those previously described by other workers. The dominant alteration during dehydration in our series was in the direction of a lowering of concentration of fixed base, chloride, and bicarbonate and an increase in concentration of protein. In a series clinically similar to ours, Hamilton, Kajdi, and Meeker (3) found that 56 per cent showed a subnormal concentration of total base, 40 per cent a low chloride value. The higher figures for total fixed base and for chloride which Hartmann (2) reported may have depended on the fact that his series consisted mainly of patients who were much sicker than ours and who may well have suffered a true anhydremia. Only one of our patients (case 8) showed the increase in chloride concentration at the expense of bicarbonate on which he has laid stress as a common cause of the acidosis accompanying this condition.

Total plasma electrolyte content. We would lay more emphasis, on the other hand, on the data we present concerning the total amount of electrolytes in circulation in the plasma (table 2). The majority in our group showed during dehydration a loss from circulation of total plasma fixed base, and eight out of the eleven a definite diminution in the total plasma chloride. The percentage loss of these sub- 
stances is in the great majority of instances larger than the percentage loss of plasma volume, so that if we measure the loss of water from the plasma by the loss of plasma volume, it is clear that what the circulation may lack during dehydration is not water alone but water and electrolytes together; and that the lack of electrolytes may be proportionately more severe. From the standpoint of the therapeutic implications of these studies it is equally clear that one cannot under these circumstances expect to relieve the symptom of dehydration by the administration of water alone or of water in combination with non-electrolyte substances such as glucose.

Composition of fluid leaving the plasma in dehydration. Some idea of the composition of the fluid lost from the plasma may be obtained by calculating the composition of the plasma increase during the period of recovery. The errors involved in such a computation are rather large, and preclude a too strict or literal interpretation of the results; moreover, only when the change in plasma volume from dehydration to recovery is great are these errors sufficiently small to justify such a calculation. For this reason we shall report the composition of the lost plasma fluid only in Case 11, in which the change in plasma volume was greatest and that in cell volume was not appreciable. It is understood also that this involves the precarious assumption that the transition from health to the dehydrated state involves exactly the opposite change from that observed during the interval between dehydration and the second determination of plasma electrolytes. For this patient, the composition of the lost plasma so calculated was:

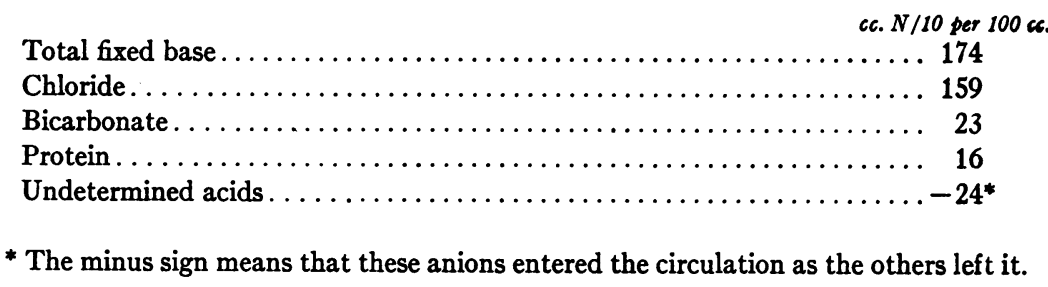

It will be observed that this represents a hypertonic solution of electrolytes. The errors of determination referred to deter us, however, from making therapeutic recommendations based on these observations.

Factors determining acidosis. This report includes no examples of 
the more severe forms of acidosis. There are certain features, however, which may throw light on the mechanism of development of acidosis under the conditions prevailing. If we arrange the cases in a series in the order of increasing concentration of serum bicarbonate at the time of dehydration, plot the curve of bicarbonate determinations, and on the same coordinates plot the curve of other functions in the same order of cases, the following tendencies are suggested: (1) The patients with low serum bicarbonate are those with subnormal temperature, with a high concentration of serum chloride, and with a relatively large amount of total circulating plasma chloride as shown by the figures for the total plasma chloride during dehydration per kilogram of body weight at that time. (2) There is no parallelism between the tendency to acidosis and the degree of diminution in plasma volume during dehydration (since this diminution may be brought about by a loss of water bound to a neutral mixture of electrolytes), nor is there a demonstrable relationship to the total amount of base lost from the plasma. (3) On the other hand, the patients with low bicarbonate were those showing a low percentage loss of chloride from the plasma; in other words, if the fluid lost from the plasma during dehydration is accompanied by a relatively large amount of base bound to chloride, acidosis is not engendered. This adds confirmation to the now familiar conception $(2,3,4)$ that a retention of chloride (or smaller loss relative to base loss) is a frequent factor in the acidosis of diarrhea. (4) It can also be shown where there is a large loss of base not bound to chloride, and therefore mainly bound to weak acids, acidosis tends to appear. It must be borne in mind, however, in the interpretation of correlations of this kind, that the method gives no clue as to which of two variables is cause and which effect, or whether any such causal relationship exists at all.

With regard to the therapy of acidosis in the presence of a high serum chloride concentration, one of our patients (case 8) showed rapid and satisfactory recovery, with restoration of serum bicarbonate to normal, after the parenteral administration of salt solution alone and without the use of bicarbonate or any other alkali by mouth. If, as now seems most likely, such chloride retention arises from a functional derangement of the kidney whereby the body loses its ability to eliminate chloride bound to the ammonium radical in the urine, 
the restitution of a normal serum electrolyte balance is shown in this instance to be possible when kidney function is restored by whatever means - whether by the injection of salt solution or of some preparation like glucose solution chosen presumably for its diuretic effect (2). Moreover, the experience in this case shows that it is not invariably necessary, in the presence of a chloride acidosis, to resort to alkali therapy provided adequate measures are taken to restore active secretion of urine.

Dehydration of subcutaneous tissues. The degree of dehydration of the subcutaneous tissues, as estimated by the crude quantitative standards described and separated into four grades, shows a suggestive correlation with changes in blood volume in the sense that the milder cases of dehydration suffered the greater diminution of blood volume. In this respect the behavior of plasma volume was more striking. In a series of this size, this may be simply a coincidence; certainly such a correlation was not anticipated, for one might have expected just the opposite-namely, that the patients with most marked lowering of plasma volume would also show the most marked dehydration of the subcutaneous tissues by the usual clinical tests. An explanation for this apparent discrepancy may lie in the factor of the time required for plasma loss to be replaced from intercellular fluid reservoirs, so that when diarrhea has been going on for only a short time the resulting plasma loss has not been met and the plasma has been affected more than the subcutaneous tissues. Of the patients with "slight" or "mild" dehydration, the average duration was 4 days; of those with "moderate" or "severe" dehydration, the average was 15 days. On the other hand, there is evidence from other sources that the response of fluid reservoirs to a need for fluid on the part of the circulating plasma is met in a much shorter time-a matter of minutes. When the body temperature in rabbits is raised, an increase of plasma volume may be detected within an hour (15); and Curtis (20) has shown that a diuresis equivalent to about one-third the entire blood volume may occur within 50 minutes in response to injection of a theophyllin derivative, the fluid presumably being drawn from intercellular reservoirs and conveyed to the kidneys, of course, in the blood. A satisfactory discussion of dehydration of the subcutaneous tissues obviously must await the development of better means of measuring it. 
We were not able to demonstrate any close correlation between the severity of "toxicity" and changes in the circulation such as alterations of blood or plasma volume or of the concentration or the total amount of circulating electrolytes. Neither could we show any relationship to serum protein concentration, an increase of which is according to Schiff (19), so closely bound up with the origin of intestinal intoxication. In our series, it by no means followed that the patients showing the most marked lowering of bicarbonate exhibited also the most toxic behavior. As long as the means of obtaining a quantitative measure of the degree of this so-called intoxication are as crude as they are at the present time, the investigation of its origin promises many difficulties.

Plasma proteins. The behavior of the plasma protein component was not uniform: sometimes dehydration was accompanied by a decrease in the total plasma protein (though with no change in serum protein concentration), suggesting that the fluid leaving the circulation under these conditions contained protein in addition to inorganic electrolytes and may possibly have approached the compositon of normal plasma, as found by Darrow and Buckman (5); at other times, there was a decrease in total plasma protein during convalescence from dehydration, a possible explanation for which is the starvation to which the patients were subjected in the course of their treatment. The plasma protein changes did not parallel the cell volume changes.

Comparison of blood during dehydration with normal averages. We have already referred to the questionable validity of the assumption that the second set of determinations made in our series represents normal values for that individual. Granted that the patient had been through a serious illness and a period of more or less strenuous treatment, we can only say that he showed at the second analysis no clinical evidence of dehydration, and we have reported these values as found.

Another course is open to us, in that we can compare the values found during dehydration with normal values obtained with the same technique $(3,6)$, the normal blood volume being calculated on the basis of the body weight. Since this allows us to include patients in whom determinations were made during dehydration but whose death prevented our obtaining a second set for comparison, the series can be 
augmented to 19 cases. Without reporting this analysis of data in detail but simply using it as a check on the results already given, we find that it essentially substantiates the statements made in regard to blood and plasma changes in dehydration of this type.

\section{SUMMARY}

Eleven infants suffering from dehydration associated with diarrhea were subjected to simultaneous determination of total blood volume and serum electrolyte concentration, both during dehydration and after recovery. In the presence of acute symptoms of dehydration some patients showed no essential change in total blood volume, while others showed a diminution amounting to 20 per cent of the recovery value. When this reduction was marked, it involved principally the plasma fraction, in one instance to the extent of 30 per cent of the recovery figure. There was no close parallelism between the diminution of plasma volume and (1) the degree of dehydration of the subcutaneous tissues as determined by clinical criteria or (2) the severity of toxic symptoms. Most of the patients showed during dehydration a decrease in the serum concentration of total fixed base, chloride, and bicarbonate; but the degree of acidosis, as measured by the serum bicarbonate concentration, could not be correlated with changes in blood or plasma volume, since the patient whose plasma loss was greatest for the whole series had a higher bicarbonate concentration on admission than after recovery. Before treatment had been given, the lowering of the total plasma electrolyte content was sometimes even greater than the loss of plasma water, when measured as percentage deviations from the presumably normal values found after recovery. Protein was often included among the electrolytes lost from the plasma during dehydration, so that the composition of the fluid leaving the circulation was comparable to that of plasma of normal protein and bicarbonate content but concentrated in respect to fixed base and chloride.

The factors governing the development of acidosis associated with dehydration and diarrhea have been briefly discussed, but little emphasis is placed on acidosis as a symptom, since it was not prominent in this series. One patient suffering from a moderate degree of acidosis due to a high concentration of serum chloride was successfully 
treated without the use of alkalis and by parenteral injection of sodium chloride solution alone.

The factors influencing the degree of dehydration of the subcutaneous tissues and the severity of toxic manifestations cannot be satisfactorily discussed until more reliable criteria for their quantitative evaluation are available.

As a check on the assumption that the second set of determinations, made after recovery from dehydration but not always at a time of complete clinical recovery, represented normal values for the individual studied, the figures obtained during dehydration were compared with normal values obtained by applying the same technical procedures to healthy infants. This comparison substantiated the results already expressed.

\section{BIBLIOGRAPHY}

1. Marriott, W. McK., Physiol. Rev., 1923, iii, 275. Anhydremia.

2. Hartmann, A. F., Am. J. Dis. Child., 1928, xxxv, 557. Chemical Changes Occurring in the Body as the Result of Certain Diseases. I. The Effects of Diarrhea, Vomiting, Dehydration and Oliguria on the Acid-base Balance of the Plasma of Infants with Mastoiditis.

3. Hamilton, B., Kajdi, L., and Meeker, D., Am. J. Dis. Child., 1929, xxxviii, 314. The Acidosis of Acute Diarrhea in Infancy.

4. Schiff, E., Bayer, W., and Fukuyama, M., Jahrb. f. Kinderh., 1928, cxix, 161. Zur Pathogenese der Ernährungsstörungen des Säuglings. Xl. Das Säurebasengleichgewicht bei der experimentellen Exsikkose.

5. Darrow, D. C., and Buckman, T. E., Am. J. Dis. Child., 1928, xxxvi, 248. The Volume of the Blood. II. The Volume of the Blood and Concentration of Crystalloids and Electrolytes in Dehydration and Edema.

6. McIntosh, R., J. Clin. Invest., 1929, vii, 203. The Determination of Circulating Blood Volume in Infants by the Carbon Monoxide Method.

7. Van Allen, C. M., J. Am. Med. Assoc., 1925, lxxxiv, 202. An Hematocrit Method.

8. Went, S., and Drinker, C. K., Am. J. Physiol., 1929, lxxxviii, 468. A Micromethod for Determination of the Absolute Blood Volume, with Data upon the Blood Volume of the Guinea Pig, White Rat, Rabbit, and Cat.

9. Fiske, C. H., J. Biol. Chem. 1922, li, 55. A Method for the Estimation of Total Base in Urine.

10. Fiske, C. H., and Sokhey, S. S., J. Biol. Chem., 1925, 1xiii, 309. Ammonia and Fixed Base Excretion after the Administration of Acid by Various Paths. 
11. Van Slyke, D. D., and Neill, J. M., J. Biol. Chem., 1924, lxi, 523. The Determination of Gases in Blood and Other Solutions by Vacuum Extraction and Manometric Measurement. I.

12. Greenberg, D. M., J. Biol. Chem., 1929, lxxxii, 545. The Colorimetric Determination of the Serum Proteins.

13. Van Slyke, D. D., Hastings, A. B., Hiller, A., and Sendroy, J., Jr., J. Biol. Chem., 1928, lxxix, 769. Studies of Gas and Electrolyte Equilibria in Blood. XIV. The Amounts of Alkali Bound by Serum Albumin and Globulin.

14. Chang, H. C., Harrop, G. A., Jr., and Schaub, B. M., J. Clin. Invest., 1928, v, 407. The Circulating Blood Volume in Diabetic Acidosis.

15. McIntosh, R., Kajdi, L., and Meeker, D. The Response of Plasma Water and Electrolytes to Elevation of Body Temperature. To be published.

16. Soule, H. C., Buckman, T. E., and Darrow, D. C., J. Clin. Invest., 1928, v, 229. Blood Volume in Fever.

17. Eppinger, H., and Schürmeyer, A., Klin. Wchnschr., 1928, vii, 777. Ubber den Kollaps und analoge Zustände.

18. Schiff, E., Ergeb. d. inn. Med. u. Kinderh., 1929, xxxv, 519. X. Das Exsiccoseproblem.

19. Gamble, J. L., N. Eng. J. Med., 1929, cci, 909. Dehydration.

20. Curtis, G. M., J. Am. Med. Assoc., 1929, xciii, 2016. The Action of the Specific Diuretics. 